\title{
MINISTERNOTOMY VERSUS COMPLETE STERNOTOMY FOR CORONARY BYPASS OPERATIONS: NO DIFFERENCE IN POSTOPERATIVE PULMONARY FUNCTION
}

Matthias Bauer, MD

Miralem Pasic, MD, PhD, FETCS

Rail Ewert, MD

Roland Hetzer, MD, PhD, FETCS
Objectives: Less-invasive approaches in cardiac operations offer certain cosmetic advantages, but it is unclear whether there are additional positive effects with regard to the postoperative recovery of patients. The aim of this prospective and randomized study was to ascertain whether partial inferior midline sternotomy can improve pulmonary function, one of the best quantifiable parameters of postoperative recovery, after coronary artery bypass operations when compared with the standard full midline approach.

Methods: One hundred patients scheduled for elective coronary artery bypass grafting were randomized either for a full median sternotomy (standard sternotomy group, $\mathrm{n}=50$ ) or for a partial inferior sternotomy (ministernotomy group, $\mathrm{n}=50$ ). The following pulmonary features were assessed: vital capacity, forced expiratory volume, percentage of forced expiratory volume from vital capacity, total lung capacity, residual volume, maximum inspiratory pressure, and maximum expiratory pressure. Tests were performed preoperatively and on the fourth and tenth postoperative days.

Results: On the fourth postoperative day, both groups had a significant decrease in vital capacity (percentage of predicted values) when compared with preoperative values (preoperative vs fourth day: standard sternotomy group, $87.8 \% \pm 14.3 \%$ vs $42.1 \% \pm 10.2 \%[P<.0001]$; ministernotomy group, $84.5 \% \pm 14.3 \%$ vs $41.5 \% \pm 11.8 \%[P<.0001])$, with a significant tendency for recovery from the fourth to the tenth postoperative day (fourth vs tenth postoperative day: standard sternotomy group, $42.1 \% \pm 10.2 \%$ vs $66.3 \% \pm 12.3 \%[P=.001]$; ministernotomy group, $41.5 \% \pm 11.8 \%$ vs $61.3 \%$ $\pm 13.1 \%[P=.002])$. There were no differences in any test results between the groups on either the fourth or the tenth postoperative day.

Conclusion: A less-invasive approach for coronary artery bypass operations with a partial inferior sternotomy does not improve early postoperative pulmonary function when compared with the conventional approach with a full sternotomy. (J Thorac Cardiovasc Surg 2001;121:702-7)
A partial inferior median sternotomy, a new approach in cardiac operations, clearly offers an important cosmetic advantage when compared with the standard sternotomy because of a shorter skin incision and a more acceptable postoperative scar. In contrast to the conventional full-length sternotomy, a partial inferior sternotomy does not include splitting of the proximal part of the sternum (manubrium sterni) and therefore preserves the stability of the superior thoracic aperture.

From the Deutsches Herzzentrum Berlin, Berlin, Germany.

Copyright (C) 2001 by The American Association for Thoracic Surgery

0022-5223/2001 $\$ 35.00+0 \quad \mathbf{1 2 / 1 / 1 1 1 3 8 0}$

doi:10.1067/mtc.2001.111380
However, it is unclear whether it has additional positive effects with regard to the postoperative recovery of the patients. Theoretically, the ministernotomy should result in more chest stability and less postoperative pain, which should result in better postoperative pulmonary function and therefore better postoperative recovery than that seen in patients who undergo a total median sternotomy. To date, there is no study to prove these theoretic advantages of the less-invasive approach for coronary bypass grafting. The aim of this prospective randomized study was to compare postoperative pulmonary function in patients who undergo elective coronary artery bypass operations, either through a partial inferior median sternotomy or through a standard complete median sternotomy. 
Table I. Demographic and operative data

\begin{tabular}{lccc}
\hline & $\begin{array}{c}\text { Standard } \\
\text { sternotomy } \\
\text { group }(n=50)\end{array}$ & $\begin{array}{c}\text { Ministernotomy } \\
\text { group } \\
(n=50)\end{array}$ & Significance \\
\hline Aariable & $61.9 \pm 8.2$ & $62.9 \pm 9.7$ & .33 \\
Male sex (n) & 39 & 41 & \\
$\begin{array}{l}\text { Female sex (n) } \\
\text { Body mass index } \\
\quad\left(\mathrm{kg} / \mathrm{m}^{2}\right)\end{array}$ & 11 & 9 & .73 \\
$\begin{array}{c}\text { LV ejection } \\
\text { fraction }(\%)\end{array}$ & $57.0 \pm 13.2$ & $59.6 \pm 12.8$ & .37 \\
$\begin{array}{c}\text { Two-vessel } \\
\text { disease (n) }\end{array}$ & 17 & 13 & \\
$\begin{array}{c}\text { Three-vessel } \\
\text { disease (n) }\end{array}$ & 33 & 37 & \\
\hline
\end{tabular}

$L V$, Left ventricular.

\section{Patients and methods}

One hundred patients who underwent elective first-time coronary artery bypass grafting were randomized (computergenerated randomization) into 2 groups with 50 patients in each: the conventional group with a standard complete median sternotomy (standard sternotomy group) and the less-invasive group with a partial inferior median sternotomy (ministernotomy group). The exclusion criteria for participation in the study were left ventricular function of less than $30 \%$ and a body mass index not exceeding 35 (normal value, 21-29). There were no differences in the demographic and preoperative data between the groups (Table I). The study was approved by The Ethical Committee of the Charité Medical School, Humboldt University of Berlin, and all patients provided written informed consent.

Except for the different surgical approaches (ministernotomy vs standard sternotomy), the operation was done with the same technique in all patients. The ministernotomy was performed according to the technique for partial inferior sternotomy described by Moreno-Cabral ${ }^{1}$ and further modified by Walterbusch. ${ }^{2}$ It includes complete median splitting of the corpus sterni. The manubrium sterni was cut from the corpus sterni in an inverted V-shaped line in the second intercostal space (Fig 1). This type of partial sternotomy allows aortic cannulation near the pericardial fold, obviates the need for a special retractor for the manubrium, and helps to keep the skin incision as short as possible. The standard instruments, cannulas, and heart-lung machine were the same for both types of sternotomy and for further surgical procedures. In brief, operations were carried out either through a standard full median or a partial inferior median sternotomy (according to the randomization) by using standard cardiopulmonary bypass and moderate systemic hypothermia of $30^{\circ} \mathrm{C}$. Cardioplegic arrest was obtained with aortic root infusion of crystalloid cardioplegic solution (Cardioplegin), followed by the infusion of cold hydroxyethylene starch solution and topical cooling. Myocardial protection was maintained by repeated infusion of cold hydroxyethylene starch solution every 20 minutes there-

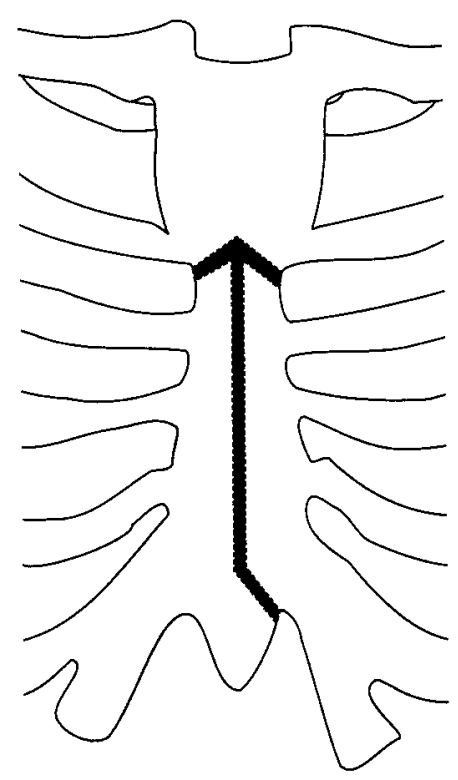

Fig 1. A diagram of the ministernotomy. Partial inferior sternotomy includes splitting of the corpus sterni, but the manubrium sterni is left intact.

after. Aprotinin (1.5 million KIU into the pump prime and $500,000 \mathrm{KIU} / \mathrm{h}$ intravenously) was given if the patient had received platelet inhibitors in the 7 days before the operation. The mean number of distal anastomoses per patient was $2.9 \pm$ 0.52 (range, 2-4 anastomoses) for the ministernotomy group and $2.8 \pm 0.64$ (range, 1-4 anastomoses) for the standard sternotomy group (difference between the groups, $P=.561$ ). If revascularization of the left anterior descending artery was indicated, the left internal thoracic artery (LITA) was used. Therefore, it was used in $48(96 \%)$ patients of the group with the ministernotomy and in $40(80 \%)$ patients with the standard sternotomy. LITAs were harvested by the no-touch technique and without opening the left pleural space. When used, the LITA was always anastomosed to the left anterior descending artery. The anesthesia protocol included induction with etomidate and fentanyl, pancuronium for muscle relaxation, and propofol infusion for maintenance of anesthesia. The postoperative management of the patients was according to the standard protocol of our institution. A standard postoperative regimen of analgesic medication includes piritramide, $7.5 \mathrm{mg}$, or morphine, $5.0 \mathrm{mg}$, intravenously up to 6 times every 24 hours during the first 2 to 3 postoperative days and later includes tramadol, 20 drops 3 times per day orally.

Pulmonary function was assessed by means of constant volume body plethysmography (Master Lab, Jäger, Würzburg, Germany). For final analysis, we selected vital capacity (VC), forced expiratory volume in 1 second $\left(\mathrm{FEV}_{1}\right)$, percentage of forced expiratory volume in 1 second from $\mathrm{VC}$, total lung capacity (TLC), and residual volume. Muscle-related breath impulse was assessed by measuring maximum inspiratory pressure and maximum expiratory pressure. All measurements were 


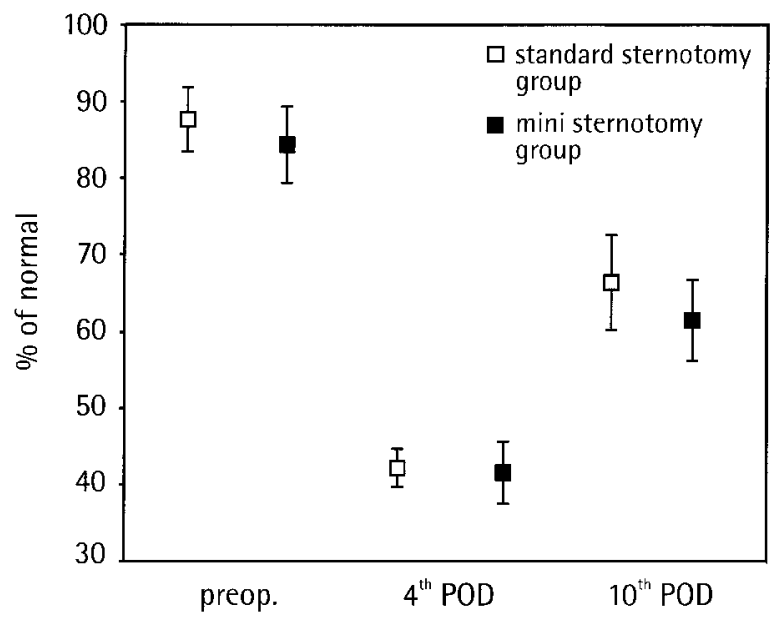

Fig 2. Courses of VC after coronary artery bypass operations in 50 patients with a standard full median sternotomy and 50 patients with a partial inferior sternotomy. The values are shown as percentages of predicted normal values. Statistical significance ( $P$ values) for the comparisons of the preoperative values versus values on the fourth postoperative day, fourth versus tenth postoperative day, and preoperative versus tenth postoperative day, respectively, was as follows: $P<$ $.0001, P<.0001, P<.0001$ for the standard sternotomy group and $P<.0001, P<.002, P<.0001$ for the ministernotomy group. Statistical significance ( $P$ values) for the comparisons of the values between the standard sternotomy group and the ministernotomy group preoperatively on the fourth and tenth postoperative days, respectively, was as follows: $P=.31, P=.80$, and $P=.20$. $P O D$, Postoperative day.

done according to the guidelines of the European Respiratory Society and expressed in percentages of predicted values. ${ }^{3}$

The tests were performed preoperatively and on both the fourth and the tenth postoperative days. The last 2 were done at our institution on an outpatient basis.

The following nonpulmonary data were assessed: total operation time, pump time, aortic clamp time, intubation time, time spent in the intensive care unit and the hospital, postoperative blood loss during the first 24 hours, and transfusion requirements.

Results are given as means \pm SD. The data of pulmonary function are presented both as a percentage of normal value and as absolute values, and all measurements are compared against both types of data, respectively. Statistical analysis was done by the Student $t$ test or the Mann-Whitney $U$ test.

\section{Results}

After coronary artery bypass operations, the values of the pulmonary function parameters $\mathrm{VC} \mathrm{FEV}_{1}$, TLC, residual volume, maximum inspiratory pressure, and maximum expiratory pressure dropped significantly on

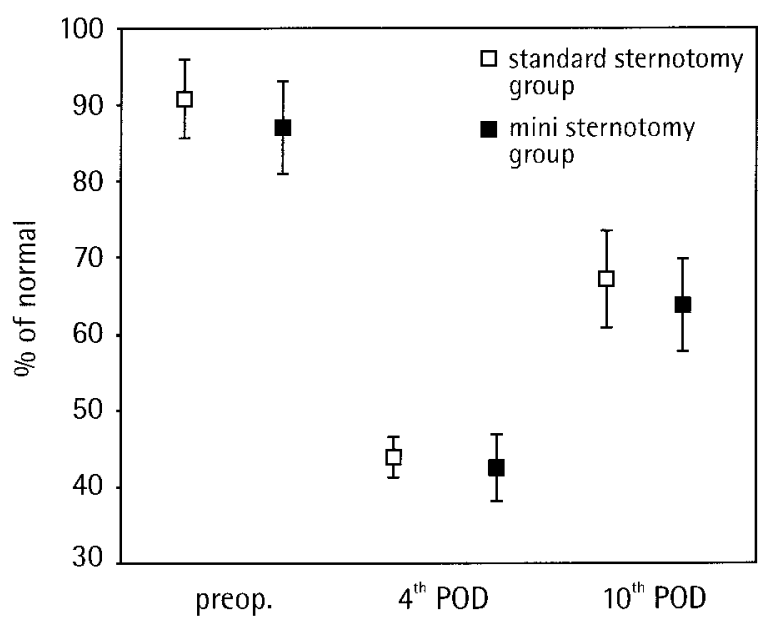

Fig 3. Courses of $\mathrm{FEV}_{1}$ (mean $\pm 95 \% \mathrm{CI}$ ) after coronary artery bypass operations in 50 patients with a standard full median sternotomy and 50 patients with a partial inferior sternotomy. The values are shown as percentages of predicted normal values. Statistical significance ( $P$ values) for the comparisons of the preoperative values versus values on the fourth postoperative day, values on fourth versus tenth postoperative day, and preoperative versus tenth postoperative day, respectively, was as follows: $P<.0001, P<.0001$, and $P<.0001$ for the standard sternotomy group and $P<.0001$, $P<.0001$, and $P<.0001$ for the ministernotomy group. Statistical significance ( $P$ values) for the comparisons of the values between the standard sternotomy group and the ministernotomy group preoperatively on the fourth and tenth postoperative days, respectively, was as follows: $P=.35, P=.57$, and $P=.43$. $P O D$, Postoperative day.

the fourth postoperative day in both groups (Figs 2 and 3 and Tables II and III). Thereafter, the values of VC, $\mathrm{FEV}_{1}$, and TLC improved in both groups until the tenth postoperative day, but they did not reach the preoperative values. However, there were no differences in any test results between the 2 groups on either the fourth or the tenth postoperative days (Figs 2 and 3 and Tables II and III).

On the fourth postoperative day, the ministernotomy group and the standard sternotomy group had VCs of 1.7 $\pm 0.6 \mathrm{~L}$ and $1.7 \pm 0.4 \mathrm{~L}$, respectively, which were calculated to be $48.5 \% \pm 13 \%$ and $50 \% \pm 12 \%$ (difference between the groups, $P=.7$ ) of the preoperative values, respectively. When expressed as percentages of predicted value, the levels of VCs on the fourth day and preoperatively were $42.1 \% \pm 10.2 \%$ and $87.8 \% \pm 14.3 \%(P<$ $.0001)$, respectively, for the standard sternotomy group and $41.5 \% \pm 11.8 \%$ and $84.5 \% \pm 14.3 \%(P<.0001)$, respectively, for the ministernotomy group (Fig 2). On the tenth postoperative day, there were also no statisti- 
Table II. Lung function parameters in the standard sternotomy group preoperatively and on the fourth and tenth postoperative days

\begin{tabular}{|c|c|c|c|c|c|c|c|c|}
\hline $\begin{array}{l}\text { Lung function } \\
\text { parameter }\end{array}$ & $\begin{array}{c}\text { Preoperative } \\
\text { absolute } \\
\text { value }\end{array}$ & $\begin{array}{c}\text { Preoperative \% } \\
\text { of normal }\end{array}$ & $\begin{array}{c}\text { 4th POD } \\
\text { absolute value }\end{array}$ & $\begin{array}{c}\text { 4th POD \% } \\
\text { of normal }\end{array}$ & $\begin{array}{c}\text { 4th POD \% of } \\
\text { preoperative } \\
\text { value }\end{array}$ & $\begin{array}{c}\text { 10th POD } \\
\text { absolute value }\end{array}$ & $\begin{array}{l}\text { 10th POD } \\
\text { \% of normal }\end{array}$ & $\begin{array}{c}\text { 10th POD \% of } \\
\text { preoperative } \\
\text { value }\end{array}$ \\
\hline VC (L) & $3.4 \pm 0.8$ & $87.8 \pm 14.3$ & $1.7 \pm 0.4$ & $42.1 \pm 10.2$ & $49.6 \pm 12.3$ & $2.7 \pm 0.7$ & $66.3 \pm 12.3$ & $73.4 \pm 16.2$ \\
\hline $\mathrm{FEV}_{1}(\mathrm{~L})$ & $2.7 \pm 0.7$ & $90.8 \pm 17.9$ & $1.3 \pm 0.4$ & $43.7 \pm 11.2$ & $49.4 \pm 12.4$ & $2.1 \pm 0.5$ & $67.2 \pm 12.8$ & $70.6 \pm 9.6$ \\
\hline $\mathrm{FEV}_{1} \% \mathrm{VC}(\%)$ & $78.8 \pm 9.4$ & $103.4 \pm 11.9$ & $80.2 \pm 12.4$ & $104.9 \pm 15.5$ & $101.0 \pm 14.8$ & $77.1 \pm 5.8$ & $101.0 \pm 6.6$ & $97.8 \pm 9.1$ \\
\hline $\mathrm{TLC}(\mathrm{L})$ & $6.2 \pm 1.2$ & $96.8 \pm 12.8$ & $3.7 \pm 1.2$ & $57.5 \pm 14.7$ & $60.9 \pm 15.2$ & $5.3 \pm 1.1$ & $79.4 \pm 12.4$ & $79.3 \pm 9.8$ \\
\hline RV (L) & $2.8 \pm 0.9$ & $118.9 \pm 32.4$ & $2.0 \pm 0.8$ & $89.2 \pm 33.9$ & $80.6 \pm 31.9$ & $2.6 \pm 0.9$ & $105.9 \pm 31.1$ & $87.6 \pm 12.7$ \\
\hline $\mathrm{PI}_{\mathrm{MAX}}(\mathrm{kPa})$ & $7.4 \pm 2.7$ & $71.5 \pm 26.6$ & $3.8 \pm 1.8$ & $36.2 \pm 17.6$ & $43.0 \pm 17.1$ & $5.4 \pm 2.6$ & $51.8 \pm 24.7$ & $79.8 \pm 17.1$ \\
\hline $\mathrm{PE}_{\mathrm{MAX}}(\mathrm{kPa})$ & $8.9 \pm 2.2$ & $67.5 \pm 16.5$ & $5.2 \pm 1.8$ & $44.9 \pm 17.0$ & $52.3 \pm 19.4$ & $6.6 \pm 2.0$ & $54.9 \pm 23.0$ & $79.0 \pm 22.4$ \\
\hline
\end{tabular}

$P O D$, Postoperative day; $F E V_{1} \% V C$, percentage of $\mathrm{FEV}_{1}$ from $\mathrm{VC} ; R V$, residual volume; $P I_{M A X}$, maximum inspiratory pressure; $P E_{M A X}$, maximum expiratory pressure.

Table III. Lung function parameters in the ministernotomy group preoperatively and on the fourth and tenth postoperative days

\begin{tabular}{|c|c|c|c|c|c|c|c|c|}
\hline $\begin{array}{l}\text { Lung function } \\
\text { parameter }\end{array}$ & $\begin{array}{c}\text { Preoperative } \\
\text { absolute } \\
\text { value }\end{array}$ & $\begin{array}{c}\text { Preoperative \% } \\
\text { of normal }\end{array}$ & $\begin{array}{c}\text { 4th POD } \\
\text { absolute value }\end{array}$ & $\begin{array}{c}\text { 4th POD \% } \\
\text { of normal }\end{array}$ & $\begin{array}{c}\text { 4th POD \% of } \\
\text { preoperative } \\
\text { value }\end{array}$ & $\begin{array}{c}\text { 10th POD } \\
\text { absolute value }\end{array}$ & $\begin{array}{l}\text { 10th POD } \\
\% \text { of normal }\end{array}$ & $\begin{array}{c}\text { 10th POD \% of } \\
\text { preoperative } \\
\text { value }\end{array}$ \\
\hline VC (L) & $3.5 \pm 0.8$ & $84.5 \pm 14.3$ & $1.7 \pm 0.6$ & $41.5 \pm 11.8$ & $48.5 \pm 12.6$ & $2.5 \pm 0.7$ & $61.3 \pm 13.1$ & $71.2 \pm 13.9$ \\
\hline $\mathrm{FEV}_{1}(\mathrm{~L})$ & $2.7 \pm 0.74$ & $87.0 \pm 17.2$ & $1.3 \pm 0.5$ & $42.4 \pm 12.6$ & $48.7 \pm 12.5$ & $2.0 \pm 0.6$ & $63.8 \pm 14.9$ & $73.7 \pm 13.4$ \\
\hline $\mathrm{FEV}_{1} \% \mathrm{VC}(\%)$ & $77.9 \pm 9.0$ & $102.6 \pm 12.4$ & $77.4 \pm 9.5$ & $102.1 \pm 12.3$ & $101.3 \pm 11.5$ & $79.0 \pm 6.7$ & $103.7 \pm 9.1$ & $103.9 \pm 9.4$ \\
\hline $\operatorname{TLC}(\mathrm{L})$ & $6.5 \pm 1.4$ & $96.5 \pm 12.8$ & $4.1 \pm 1.2$ & $59.6 \pm 13.7$ & $61.0 \pm 14.1$ & $4.9 \pm 1.2$ & $72.9 \pm 12.9$ & $71.8 \pm 13.8$ \\
\hline RV (L) & $3.0 \pm 0.8$ & $124.9 \pm 30.6$ & $2.1 \pm 0.7$ & $86.7 \pm 25.3$ & $69.0 \pm 21.5$ & $2.3 \pm 0.6$ & $98.7 \pm 21.5$ & $76.1 \pm 28.4$ \\
\hline $\mathrm{PI}_{\mathrm{MAX}}(\mathrm{kPa})$ & $7.16 \pm 1.9$ & $69.5 \pm 19.1$ & $3.8 \pm 1.6$ & $37.0 \pm 15.8$ & $65.8 \pm 26.9$ & $4.5 \pm 1.4$ & $43.1 \pm 13.2$ & $79.0 \pm 17.0$ \\
\hline $\mathrm{PE}_{\mathrm{MAX}}(\mathrm{kPa})$ & $9.1 \pm 1.1$ & $68.7 \pm 8.5$ & $5.4 \pm 2.3$ & $44.1 \pm 21.8$ & $72.3 \pm 26.4$ & $6.3 \pm 1.7$ & $53.0 \pm 21.0$ & $87.5 \pm 13.8$ \\
\hline
\end{tabular}

$P O D$, Postoperative day; $F E V_{1} \% V C$, percentage of $\mathrm{FEV}_{1}$ from $\mathrm{VC} ; R V$, residual volume; $P I_{M A X}$, maximum inspiratory pressure; $P E_{M A X}$, maximum expiratory pressure.

cally significant differences of the VC values between the groups. The ministernotomy group and the standard sternotomy group had VCs of $2.5 \pm 0.7 \mathrm{~L}$ and $2.7 \pm 0.7$ L, respectively, which were calculated to be $71 \% \pm 14 \%$ and $73 \% \pm 16 \%(P=.2)$ of the preoperative values, respectively. When expressed as percentage of predicted value, the levels of VCs on the fourth and the tenth days were $42.1 \% \pm 10.2 \%$ and $66.3 \% \pm 12.3 \%$, respectively $(P=.001)$, for the standard sternotomy group and $41.5 \%$ $\pm 11.8 \%$ and $61.3 \% \pm 13.1 \%$, respectively $(P=.002)$, for the ministernotomy group. However, there were still significant differences between the preoperative values and the actual values of VCs of each group on the tenth postoperative day (Fig 2).

The values of $\mathrm{FEV}_{1}$ on the fourth postoperative day were $1.3 \pm 0.5 \mathrm{~L}$ and $1.3 \pm 0.4 \mathrm{~L}$ for the ministernotomy group and the standard sternotomy group, respectively, which were calculated to be the $49 \% \pm 12.5 \%$ and $49 \pm 12 \%$ of the preoperative values, respectively (difference between the group on the fourth postoperative day, $P=.57$; Fig 3). The values of $\mathrm{FEV}_{1}$ on the tenth postoperative day were $2.0 \pm 0.6 \mathrm{~L}$ and $2.1 \pm 0.5$ $\mathrm{L}$, respectively, which were $74 \% \pm 12.5 \%$ and $71 \% \pm$ $10 \%(P=.43)$ of the preoperative values, respectively.
Similar to the values of VCs, the preoperative and actual values of $\mathrm{FEV}_{1}$ on the tenth postoperative day were significantly different in both groups (Fig 3).

There was no conversion from the less-invasive approach to the standard complete median sternotomy. Postoperatively, in both groups there was one patient with thoracotomy wound infection and sternal instability. There were no differences between the groups with regard to the duration of the operation, the pump time, aortic crossclamp time, use of LITAs, postoperative blood loss, duration of intubation, intensive care unit stay, and the number of days to discharge from the hospital (Table IV). The values of maximum creatine kinase and creatine kinase MB fraction were significantly higher in the ministernotomy group than in the standard sternotomy group (Table IV). These findings were not accompanied by clinical and electrocardiographic signs of perioperative myocardial infarction in any of the patients.

\section{Discussion}

Our study showed no beneficial effect of a ministernotomy on early postoperative lung function after elective coronary artery bypass grafting when com- 
Table IV. Operative and postoperative data

\begin{tabular}{lccc}
\hline Variable & Standard sternotomy group $(n=50)$ & Ministernotomy group $(n=50)$ & Significance \\
\hline Operation time (min) & $207.0 \pm 47.3$ & $192.7 \pm 35.0$ & .09 \\
Pump time (min) & $85.9 \pm 24.4$ & $76.8 \pm 22.7$ & .06 \\
Aortic clamp time (min) & $46.2 \pm 15.6$ & $42.0 \pm 11.2$ & .12 \\
No. of distal anastomoses (mean) & $2.8 \pm 0.64$ & $2.9 \pm 0.52$ & .561 \\
LITA use (No. of patients) & 40 & 48 & .092 \\
CK max (U/I) & $282.6 \pm 179.1$ & $434.2 \pm 338.1$ & .006 \\
CKMB max (U/I) & $18.0 \pm 10.8$ & $27.7 \pm 16.4$ & .0008 \\
Postoperative blood loss (mL/24 h) & $648.8 \pm 413.1$ & $600.2 \pm 332.2$ & .52 \\
Transfusion requirement (mL) & $435 \pm 100.8(\mathrm{n}=16)$ & $472 \pm 150.2(\mathrm{n}=9)$ & .56 \\
Duration of intubation (min) & $629.7 \pm 803.2$ & $483.2 \pm 208.8$ & .22 \\
ICU stay (h) & $23.9 \pm 17.8$ & $19.5 \pm 47.45$ & .11 \\
Days to discharge from hospital & $3.9 \pm 1.8$ & $3.6 \pm 1.1$ & .64 \\
\hline
\end{tabular}

$C K$, Creatine kinase; $C K M B$, creatine kinase $\mathrm{MB}$ fraction; $I C U$, intensive care unit.

pared with standard median sternotomy. Regardless of the type of sternotomy, a severe restrictive disturbance of lung function and a diminished muscle-related inspiratory impulse was noted in all patients early after their operations. The results correlate well with many lung function studies that describe the effects of cardiac procedures, ${ }^{4,5}$ especially coronary bypass operations, performed through a standard median sternotomy. ${ }^{6-8}$ We evaluated postoperative lung function because it is one of the best quantifiable parameters of postoperative recovery. In this study we performed pulmonary function tests only during the early postoperative period because it is widely known that the lung function recovers to baseline levels after a period of 3 months. ${ }^{9-12}$

We did not compare a possible difference between the postoperative analgesic requirements of the 2 study groups, and we cannot answer whether there was any difference in analgesic medication. Therefore, it remains unclear whether the lack of difference between the 2 approaches may simply be masked by increased analgesic requirement in the full sternotomy group.

Although there was no statistical difference in regard to the use of LITAs in both study groups, it could be speculated that less use of LITAs in the full sternotomy group in comparison with that in the ministernotomy group ( $80 \%$ vs $96 \%$ ) could lead to a better observed pulmonary function in this group and therefore could mask our results. However, the LITA preparation was always performed without opening the left pleural cavity, and therefore pulmonary function was further preserved, reducing the possibility of clouding the results.

The choice of a surgical approach and the type of surgical procedure are the most important factors that influence postoperative pulmonary function. A median sternotomy (a standard approach for cardiac opera- tions) preserves pulmonary function when compared with a lateral thoracotomy (a standard approach for lung resection procedures) because it is accompanied by less postoperative pain and causes no compromise of the chest muscle function. ${ }^{13,14}$ The advantages of performing a lung procedure through a median sternotomy rather than a lateral thoracotomy are widely known. ${ }^{13,14}$ However, cardiopulmonary bypass causes an important reduction of pulmonary function. Because of these negative effects of cardiopulmonary bypass, the postoperative deterioration of lung function is significantly more profound after cardiac operations than after lung resection procedures performed through the same surgical approach. ${ }^{15}$ This negative effect of extracorporeal circulation with regard to pulmonary function is significant, despite the use of the surgical approach (a median sternotomy) that spares pulmonary function. Thus, the question is whether the reduction of the sternal incision has any further positive influence on postoperative lung function. Presently, there is no study that compares pulmonary function in patients who undergo coronary bypass operations through a partial inferior sternotomy and those operated on through a full median sternotomy. Our study clearly showed that the ministernotomy has no advantages over the standard median sternotomy with regard to postoperative pulmonary function in patients who are undergoing coronary artery bypass operations. There is a similar study that considered postoperative pulmonary function in patients who underwent aortic valve replacement. ${ }^{16}$ It also failed to prove the theoretic advantages of the ministernotomy over the standard median sternotomy. The study included only 20 patients with reversed $\mathrm{L}$ or $\mathrm{C}$ ministernotomy and 20 patients with full sternotomy. Lung function tests concentrated on $\mathrm{VC}$ and $\mathrm{FEV}_{1}$, which were done only once 
postoperatively before hospital discharge. The same group published another study with 26 patients in the ministernotomy group and 14 patients in the median sternotomy group. The results were similar to those of their first study. ${ }^{17}$ Obviously, the studies of Aris and associates, ${ }^{16,17}$ as well as our study, showed that there is no beneficial effect of less-invasive approaches on postoperative lung function after cardiac operations. It seems that the significant reduction of postoperative lung function is influenced mostly by the use of cardiopulmonary bypass and not by the length of skin and sternal incisions.

In conclusion, our study failed to prove the possible theoretic advantages of the partial inferior sternotomy over the conventional median sternotomy with regard to postoperative pulmonary function. The cosmetic improvement should be considered as the main advantage of a ministernotomy over the conventional sternotomy.

We thank Guna Tetere, MD, Frank Wagner, MD, Andreas Koster, MD, Christoph Knosalla, MD, and Zrino Nakic, MD, for their contribution to the work; Ms Julia Stein for statistical analyses; Ms Tonie Derwent for editorial work; and Mr Helge Haselbach for graphic work.

Received for publication April 19, 2000; revisions requested May 25, 2000; revisions received July 7, 2000; accepted for publication Aug 29, 2000.

Address for reprints: Miralem Pasic, MD, PhD, FETCS, Deutsches Herzzentrum Berlin, Klinik für Herz-, Thoraxund Gefässchirurgie, Augustenburger Platz 1, D-13353 Berlin, Germany (E-mail: pasic@dhzb.de).

\section{REFERENCES}

1. Moreno-Cabral RJ. Mini-T sternotomy for cardiac operations. J Thorac Cardiovasc Surg 1997;113:810-1.

2. Walterbusch G. Partial sternotomy for cardiac operations. J Thorac Cardiovasc Surg 1998;115:256-8.

3. European Community for Steel and Coal. Standardized lung function testing. Eur Respir J 1993;6(Suppl 16):1-100.
4. Shenkman Z, Shir Y, Weiss YG, Bleiberg B, Gross D. The effects of cardiac surgery on early and late pulmonary functions. Acta Anaesthesiol Scand 1997;41:1193-9.

5. Tulla H, Takala J, Alhava E, Huttunen H, Kari A, Manninen H. Respiratory changes after open-heart surgery. Intensive Care Med 1991;17:365-9.

6. van Belle AF, Wesseling GJ, Penn OC, Wouters EF. Postoperative pulmonary function abnormalities after coronary bypass surgery. Respir Med 1992;86:195-9.

7. Vargas FS, Terra-Filho M, Hueb W, Teixeira LR, Cukier A, Light RW. Pulmonary function after coronary artery bypass surgery. Respir Med 1997;91:629-33.

8. Wahl GW, Swinburne AJ, Fedullo AJ, Lee DKP, Shayne D. Effect of age and preoperative airway obstruction on lung function after coronary artery bypass grafting. Ann Thorac Surg 1993;56:1047.

9. Cohen AJ, Moore P, Jones C. Effect of internal mammary harvest on postoperative pain and pulmonary function. Ann Thorac Surg 1993;56:1107-9.

10. Shapira N, Zabatino SM, Ahmed S, Murphy DMF, Sullivan D, Lemole GM. Determinants of pulmonary function in patients undergoing coronary bypass operations. Ann Thorac Surg 1990;50:268-73

11. Stock MC, Downs JB, Weaver K, Lebenson IM, Cleveland J, McSweeney TD. Effect of pleurotomy and coronary bypass surgery on postoperative mechanics. Ann Thorac Surg 1986;42:441-4.

12. Berrizbeitia LD, Tessler S, Jacobowitz IJ, Kaplan P, Budzilowics L, Cunningham JN. Effect of sternotomy and coronary bypass surgery on postoperative pulmonary mechanics. Chest 1989;96:873-6.

13. Hallfeldt KKJ, Siebeck M, Thetter O, Schweiberer L. The effect of thoracic surgery on pulmonary function. Am J Crit Care 1995;4:352-4.

14. Urschel HC Jr, Razzuk MA. Median sternotomy as a standard approach for pulmonary resection. Ann Thorac Surg 1986;41:130-4.

15. Takizawa T, Haga M, Yagi N, Terashima M, Uehara H, Yokoyama A, et al. Pulmonary function after segmentectomy for small peripheral carcinoma of the lung. J Thorac Cardiovasc Surg 1999; 118:536-41.

16. Aris A, Camara ML, Montiel J, Delgado LJ, Galan J, Litvan H. Ministernotomy versus median sternotomy for aortic valve replacement: a prospective, randomized study. Ann Thorac Surg 1999;67:1583-8

17. Aris A, Camara ML, Casan P, Litvan H. Pulmonary function following aortic valve replacement: a comparison between ministernotomy and median sternotomy. J Heart Valve Dis 1999;8:605-8. 